\title{
NEXUS OF EMOTIONAL INTELLIGENCE (EI), NEED FOR AFFILIATION (NAFF), INTEGRATING STYLE OF CONFLICT RESOLUTION: A CASE STUDY OF DISPUTE RESOLUTION AMONG UNDERGRADUATES IN SRI LANKAN STATE UNIVERSITIES
}

\author{
Dissanayake, WDMBK ${ }^{1}$ and Kodagoda, DTD ${ }^{2}$ \\ Department of Business Management, Wayamba University of Sri Lanka ${ }^{1}$ \\ Department of Human Resources, University of Colombo ${ }^{2}$
}

\begin{abstract}
Emotions and motivational desires play a significant role in human behaviour. Accurate comprehension and management of those factors influence the behaviour of people. University undergraduate disputes are a heading in many mainstream dialogues in the county. Yet many have looked into it, disregarding the emotional and motivational components. The selection of conflict resolution mechanism mainly depends upon the conflicting party's motivational desire and emotions, but it is unexplored in the Sri Lankan context. Thus this study was conducted to understand how the nexus of motivational desire (i.e., Need for Affiliation (nAff)) and Emotional Intelligence (EI) influence the selection of conflict resolution styles (i.e., behaviour) among undergraduates to bridge the prevailing gap. A survey conducted involved the participation of 388 undergraduates from ten (10) state universities. The measurements were; EI - Wong and law EI scale, nAff - Unified Motive Scales (UMS), conflict resolution styles (integrating style) - Rahim's Organizational Conflict Inventory-II. Moderated multiple regression analysis (hierarchical multiple regression) was applied to test the hypothesis. The results signify that emotionally intelligent people prefer to use an integrating style to resolve conflicts. Further, motivational desires, i.e., nAff (moderating variable), enhanced the relationship between EI and selecting an integrating style to resolve conflicts. It indicates that those emotionally intelligent and highly needed affiliations tend to choose a more productive and collaborative conflict resolution approach such as integrating style. Students' emotional intelligence (EI) levels will rise due to opportunities to strengthen their relationships and EI development programmes. That leads to selecting more productive conflict resolution approaches such as integrating style to manage student conflict better.
\end{abstract}

Future researchers could enhance the study by adding personality, values, and cultural elements to the model.

KEYWORDS: nAff, EI, Integrating conflict resolution style, State University, Undergraduates

Corresponding author: Dissanayake, WDMBK Email: bimba@wyb.ac.lk 


\section{INTRODUCTION}

Conflict is a natural consequence of diversity due to cognition and social interaction aspects of human behaviour (Popescu and Vasilescu, 2012); thus, it has an inevitable appearance in the social context (Darling and Walker, 2001). According to some workers, there are diverse views about the conflict, and as a negative phenomenon (Jehn, 1997; Pondy, 1967; Robbins and Judge, 2013), must avoid at any cost. A concept (if well managed) can deliver functional results (De Dreu and Van de Vliert, 1997). Conflicts can arise within individuals, groups, parties, or entities (De Dreu \& Gelfand, 2008), i.e., Individual-level conflicts - a conflict that can take a particular form. These conflicts affect only individual and individual motivation, cognitions, and affective states determine the conflict process. Group level conflicts - Intra-group conflicts within an internal group, team, or department and Intergroup conflicts between different groups, teams, and departments. Organizational level conflicts - conflicts between different organizations (substantive, emotional, and cultural). Another classification demarcates conflicts into three domains; Task conflicts which relate to the content and the goals of the work, Relationship conflicts which focus on interpersonal relationships and Process conflicts which relate to how the work gets done (Robbins \& Judge, 2013). Research indicates low levels of process conflict and low to moderate levels of task conflict can be functional, but any level of relationship conflict is dysfunctional all the time. These findings are not applicable in every context. It is essential to remember that these functions get influenced by many other factors and need collaborative management. Fleetwood (1987) suggests that since conflict is unavoidable, managers must recognize the sources of conflict, view its constructive and destructive potential, learn how to manage conflict, and implement conflict resolution techniques effectively. Predominantly, conflict management strategies determine whether the outcomes are constructive or destructive (Park and Antonioni, 2007).

Emotional Intelligence (EI) is an antecedent of conflict resolution strategies (Shih and Susanto, 2010). Jones (2000) elaborated that human conflict does not exist in the absence of emotions, while Bodtker and Jameson
(2001) favourably argue that if a person is in a conflict situation, he must be emotionally charged. Consequently, conflict is an emotionally created and emotionally driven process, and proper identification of emotion involved in a conflict process exposes the opportunities to orchestrate the conflict management productively (Jordan and Troth, 2004; Eadie and Nelson, 2001; Bodtker and Jameson, 2001). Further Human behaviour is essentially formed under the influence of the person's motivations to achieve specific goals (Raeisi et al., 2012).

Motivation is the force within the individual that influences or directs the behaviour (Mrayyan, Modallal, Awamreh, Atoum, Abdullah, \& Suliman, 2008) that accounts for an individual's intensity, direction, and persistence of effort toward attaining a goal (Robbins \& Judge, 2013). Proper understanding of human motivation is a valuable dimension to predict the causes of human behaviour. McClelland (1987) identified three motivational drivers who drive human behaviour as the need for achievement (nAch), the need for Power (nPow), and the need for affiliation (nAff). If a person has a fundamental need or desire to be with other people, seek and grab the opportunities to interact with other people, such a person is said to be driven by the need for Affiliation (McClelland,1987).

Even though there has been some research on the impact of EI and motivation on conflict (Rahim et al., 2002; Chan et al., 2014; Bodtker and Jameson, 2001; Bell and Blakeney, 1977), scholars have not yet attempted to address the integrative impact of the two on conflict resolution strategy. It is crucial to test the simultaneous impact of the EI level associated with the motivational drive on selecting a conflict resolution strategy to have a more accurate result.

Sri Lankan university undergraduates are known to adopt an aggressive approach to conflict resolution. It is evident through the frequent student clashes, staffstudent conflicts, and rivalry (Ruberu, 2003). The closing of universities due to student unrest, the postponement of admissions and examinations due to students not participating in the scheduled programmes, and frequent student protests have given university administration a serious problem. University undergraduate conflict, which is a group-level 
relationship conflict, has transformed itself from intrauniversity issues to national ones (Weeramunda, 2008; Hennayake, 2008). University undergraduates have the most refined intellect among Sri Lankan advanced level students and are the prospected prominent drivers of the country. These privileged few are the cream of the nation with all the potential to take the country to new heights (Hennayake, 2008). Hence addressing their critical behavioural issues is obligatory.

The conflict in human behavior gets influenced by many factors such as emotions, emotional intelligence (Goleman \& Cherniss, 2001; Salovey \& Mayer, 1990), motivational desire (Robbins \& Judge, 2013; Raeisi, Hadadi, Faraji, \& Salehian, 2012).

However, even though scholars have looked into the concept of conflict resolution, many have looked into it, disregarding its emotional and motivational components. The selection of conflict resolution mechanism (i.e., behaviour) mainly depends upon the motivational desire (i.e., nAff) and emotions (i.e., EI) of the parties involved in the conflict. Still, these are yet unexplored in the Sri Lankan context. Thus, this research aims to analyse the integrative impact of the EI and motivation towards selecting a conflict resolution strategy bridging the research gap as mentioned above.

The study expects to find answers to 1) whether emotional intelligence influences selecting Integrating conflict resolution style, and 2) whether the need for affiliation moderates the relationship between emotional intelligence and integrating conflict resolution style.

\section{Conflict and conflict resolution}

Conflicts have continued to exist everywhere from the very beginning of society. It is a natural consequence of diversity due to cognition and social interaction aspects of human behaviour (Popescu and Vasilescu, 2012); thus, it inevitably appears in the social context. Thomas (1992) defines conflict as "the process which begins when one party perceives that another has frustrated, or is about to frustrate, some concern of his" (p. 891). While conflicts remain static, the way people perceive the same evolved with time. Some viewed conflict negatively and discussed it with such terms as violence, destruction, and irrationality. In this arena, the conflict got identified as an inevitable outgrowth of the social class system or organisation hierarchy that hinders the performance of organisations; it is dysfunctional and essentially needs to be avoided (Jehn, 1997; Pondy, 1967; Robbins and Judge, 2013). Others suggest that conflicts are beneficial and enhance organisational performances, thus proposing its acceptance and utilisation of its outcomes to better organisational performance.

Conflict Resolution strategies refer to particular behavioural patterns that a person prefers to employ when confronting a conflict situation (Rahim, 2002; Rahim et al., 2002; Ma, 2005). Among many models of conflict resolution strategy (Kilmann and Thomas, 1977; Rahim, 1983), the study considered the integrating style of Rahim's five types of interpersonal conflict handling model (Rahim, 1983). Rahim's five types of conflict handling styles, as shown in figure 1, consisted of five types: integrating, obliging, compromising, dominating, and avoiding based on two fundamental dimensions, i.e., concern for self (the extent to which a person attempts to satisfy own needs) and concern for others (the extent to which a person tries to satisfy others' needs).

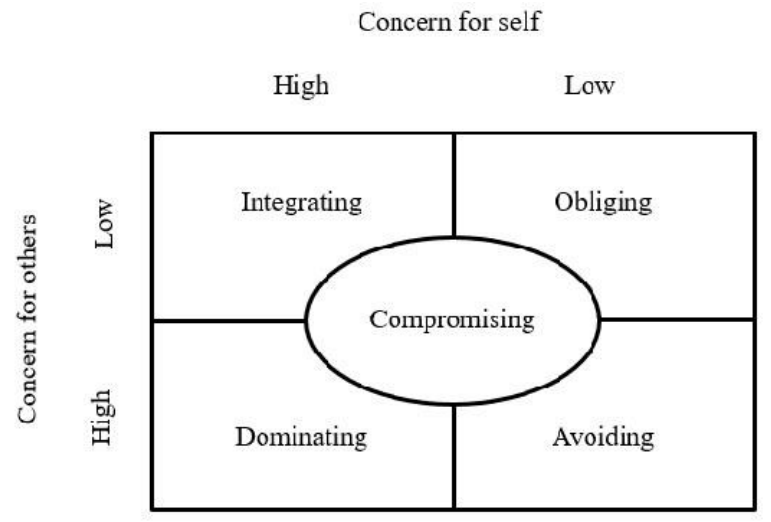

Figure 1: Rahim's five interpersonal conflict styles (Rahim, 1983, p.369)

Integrating style (a serious concern for self and others) attempts to satisfy the concerns of both parties and tries to achieve a win-win solution that is mutually beneficial for both parties (Robbins and Judge, 2013). The style involves openness, exchanging information, and examining differences to reach a practical, acceptable 
solution for both parties. The integrating style is associated with another classification that demarcates conflicts into three domains, i.e., Task conflicts that relate to the content and goals of the work, Relationship conflicts that focus on interpersonal relationships, and Process conflicts that relate to how the work gets done (Robbins \& 20 Judge, 2013). Research indicates that low levels of process conflict and low to moderate levels of task conflict can be functional, but any level of relationship conflict is dysfunctional all the time. These findings are not applicable in every context. It is important to note that many other factors may influence these functions, and thus collaborative management is needed. To reduce conflict by using collaboration rather than minimising organisational conflicts is the ultimate goal of problem-solving. (Antonioni, 1998). (Barbuto $\mathrm{Jr}$ and $\mathrm{Xu}, 2006$ ). Problem-solving, collaboration, cooperation, solution-oriented, and winwin or positive-sum styles are other terms used to describe this approach. According to Gross and Guerrero (2000), the most accepted integrative style is appropriate, effective, and competent when resolving disputes.

\section{Emotional Intelligence (EI)}

Salovey and Mayer (1990), who propounded EI, define it as an individual's ability to recognise emotions of one's own and those of others in a manner that allows them to monitor them, distinguish among different emotions, and use this information effectively in shaping one's behaviour. Goleman (1998) identified EI under four dimensions of self-awareness, selfmanagement, empathy, and social skill and defined it as the capacity to recognise our feelings and the feelings in others, motivate ourselves, and manage emotions well in us and our relationships. People who can recognise and monitor their feelings and can recognise and deal with the feelings of others have advantages in all areas of life. In contrast, those who cannot control their emotional lives constantly battle, preventing them from producing continued work and clear thoughts.

EI perspectives were different on the characteristics and dimensions, resulting in different interpretations by distinctive theorists. Wong and Law (2002) conceptualise the EI following Salovey and Mayor's (1990) in terms of four dimensions as self-emotional appraisal [SEA], others emotional appraisal [OEA], regulation of emotion [ROE], and use of emotion [UOE]. An escalating number of scholars suggest that EI has a considerable possibility of predicting workplace behaviour in organisations and contributing to understanding relationships in the work context (Salovey and Mayer, 1990; Goleman, 1998; Spielberger, 2004). individuals with well-developed EI can identify and control their own emotions and those of others. They are less likely to be paralysed by fear, hijacked by negative emotions, and strangled by anxiety, all of which negatively affect both individual and team performance (Lam and Kirby, 2002).

The link between EI and conflict is obvious. Human conflict does not exist in the absence of emotion (Jones, 2000). Conflicts are human behaviour, and they arise as a result of an emotional process. Bodtker and Jameson (2001) argue that if a person conflicts, he must be emotionally charged. One is not aware that one conflicts unless he recognises that he is emotional about something. Jordan and Troth (2002) have supported the same by exclaiming that it is naturally emotional if the conflict involves the perception of threats to individual goals. Similarly, Jordan and Troth (2004) put forward the notion that all conflicts (functional or dysfunctional) are intrinsically emotional since a conflict involves the perception of threat to an individual or a group. In light of the above findings, scholars argue that conflicts are inherently an emotionally created and driven process; thus, EI and conflict management are interconnected (Jordan and Troth, 2004; Eadie and Nelson, 2001; Bodtker and Jameson, 2001; Jones, 2000).

Understanding the role of emotions in conflict and conflict management is essential to manage them more effectively (Bodtker and Jameson, 2001). In the opinion of many academics, EI can play a critical role in effectively resolving conflicts (Jordan and Troth, 2002; Bodtker and Jameson, 2001). Those with a high level of EI can learn and use conflict management skills immediately in the workplace, solve conflicts faster and more effectively, have superior conflict resolution skills, and engage in greater collaboration. As a result, it contributes to better team performance (Cherniss and Adler, 2000; Desivilya and Yagil, 2005; Goleman, 
1998; Jordan and Troth, 2004). Therefore, this study also presumes that EI may lead people to choose more advantageous styles of handling interpersonal conflicts. The selection of constructive conflict resolution styles indicates a high EI and vice versa.

\section{Need for affiliation (nAff)}

Human motivation is the psychological drive that guides a person towards achieving a goal, underlying reason for 'how' and 'why' people behave as they do (Hegar, 2012), account for an individual's intensity, direction, and persistence of effort toward attaining a goal (Robbins and Judge, 2013) which ultimately direct the behaviour (Mrayyan et al., 2008). The three prime motivational drivers identified are the need for achievement (nAch), the need for Power (nPow), and the need for affiliation (nAff) (McClelland, 1987). nAch drives a person to put his maximum effort to achieve the goals; do better, and aspire to a standard of excellence, nPow is the desire to control and influence others; to have responsibility for their performance; to have an impact on others (Uduji and Ankeli, 2013). nAff is to establish and maintain cordial relations with other humans; often choose to spend time with close friends or significant others and satisfy the need of having a personal relationship (Raeisi et al., 2012; Uduji and Ankeli, 2013). The importance of each of these needs varies from person to person (Lilly, Duffy, and Virick, 2006). Rybnicek, Bergner, and Gutschelhofer (2017) validated the same according to that study; the relevant brain area was more activated when there was a close matching of rewards with a person's need level (nAch, nAff, nPow).

When individuals are presented with rewards more closely to their desired needs, those rewards perceives as more rewarding (Schultheiss et al., 2008; Rybnicek et al., 2017).

A person with a fundamental need or desire to be with other people seek and grab the opportunities to interact with other people, and this is said to be driven by the nAff (McClelland, 1987). The definition for nAff is the desire for friendly and close interpersonal relationships such as spending more time maintaining social relationships, joining groups, and wanting to be loved (Ramlall, 2004), choosing to spend time with close friends or significant others rather than being in any other setting.

They are sensitive to others' reactions to them, prefer collaborative, non-competitive activities (Uduji and Ankeli, 2013), and exhibit substantial conformity to other people's wishes to maintain a friendly relationship (Lilly, Duffy, and Virick, 2006).

\section{EI, nAff, and integrating style of conflict resolution}

The study of Christie et al. (2007) revealed that people who have a higher ability to regulate their emotions were more likely to be motivated by achievement needs. Those who reported high in understanding others' emotions were motivated by affiliation needs. As claimed, conflict and human motivation are closely related concepts (Barbuto $\mathrm{Jr}$ and $\mathrm{Xu}, 2006$ ). nAff positively correlated with the smoothing (cooperative) style (Jones and White, 1985). People with high EI interact well with people, possess good interpersonal skills (Goleman, 1998), and prefer collaborative conflict resolution styles (Jordan and Troth, 2002; Jordan and Troth, 2002a). Goleman (1998) suggested that individuals with high EI would have superior conflict resolution skills, engaging in greater collaboration. This assertion depends on the belief that individuals with high EI work to maintain relationships.

Similarly, McClelland (1987) proposes people who have affiliation motives seek social approval. This type of people typically desire to be fond of others and want others to like them, prefer to avoid conflict and competition with others (Lilly, Duffy, and Virick, 2006). They tend to elude problems arising from interpersonal incompatibilities and readily adjust their values or beliefs to others' to secure positive social relationships (Chatman and Barsade, 1995). According to the literature review, one can assume that there may be a complementing effect to an emotionally intelligent person driven with nAff, wanting to maintain a better relationship with others. That tends to select a more smooth conflict resolution strategy with a deep concern for their counterparties.

There are many studies available on EI and conflict resolution strategies (Ashkanasy and Daus, 2002; Bodtker and Jameson, 2001; Chan, Sit, and Lau, 2014; Di Fabio and Blustein, 2010; Jordan and Troth, 2004), 
EI and human motivational needs (Christie et al., 2007; Jones and White, 1985; Essop, 2015) and human motivational needs and conflict resolution (Fodor, 1985; Bell and Blakeney, 1977).

As per the literature review, no study exists in searching for how nAff of individual influence on the established relationship of EI and integrating conflict resolution strategy within the Sri Lankan context. Thus this study attempts to bridge the said gap by analysing the moderating impact of nAff on the relationship between EI and integrating conflict resolution strategy.

\section{Conceptual Model}

In this study, EI is used to apply as an antecedent of integrating conflict resolution styles. The Affective Event Theory (AET) states that human behaviour drives emotions of human behaviour and conflicts (Jordan and Troth, 2004; Eadie and Nelson, 2001; Bodtker and Jameson, 2001).

Higher EI might generate a sympathetic feeling that encourages individuals to consider other interests when solving conflicts. In this situation, a win-win solution may become a priority in resolving the conflicts among individuals to satisfy everyone's interests. As a result, people with high emotional intelligence may prefer the integrating style. People with high nAff prefer to maintain social relationships, join groups, and want to be loved (Ramlall, 2004). They positively link with selecting smoothing conflict resolution styles (Jones and White, 1985). The integrating style is their preferred conflict resolution style because they are relationship-oriented. In order to conduct the study, nAff serves as a moderator.

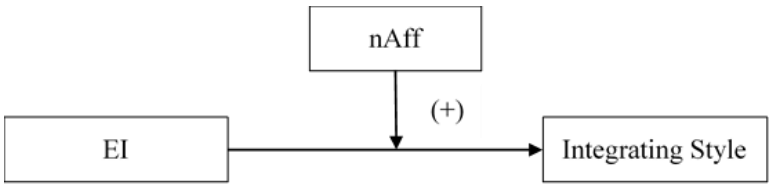

Figure 2: Conceptual Framework

The results of the studies consistently showed that individuals with high EI preferred to seek integrating solutions when confronted with conflict (Jordan and
Troth, 2002; Jones, 2000; Shih and Susanto, 2010; Gross and Guerrero, 2000; Chan, Sit, and Lau, 2014). Integrating conflict resolution patterns is positively related to positive emotions and self-efficacy and a climate of concern for organisational interest (Jones, 2000). Goleman (1998) suggested that individuals with high EI would have superior conflict resolution skills. They can better negotiate and effectively handle affairs, using an integrative approach to develop new solutions to satisfy both parties' concerns. This assertion claims on the belief that individuals with high EI work to maintain relationships (Jordan and Troth, 2002). Emotionally intelligent people may more possibly consider other people's needs and interests in solving conflicts. Thus, a win-win solution produced by integrating style facilitates an opportunity to apply their concerns in resolving the conflicts among individuals to satisfy everyone's interests (Shih and Susanto, 2010). Further, emotionally intelligent people are more likely to select integrating and compromising styles because those styles may have more beneficial outcomes in terms of efficacy and suitability (Gross and Guerrero, 2000; Morrison, 2008). Based on the above arguments, they hypothesised that;

\section{H1: EI is positively related to integrating conflict resolution strategy}

nAff, nAch, and nPow are the three motivations that shape an employee's behaviour in an organisation, according to McClelland's human motivational need theory. People with high EI interact well with people and possess good interpersonal skills (Goleman, 1998). The people who have affiliation motive seek social approval and typically desire to be fond of others and want others to like them (Lilly, Duffy, and Virick, 2006). Also, nAff positively linked with preference to select the smoothing conflict resolution style (Jones and White, 1985). Thus there may be a complementing effect, so a person with high emotional intelligence who drives from affiliation needs to prefer an integrating conflict resolution style. That directs towards the concerning needs of the other party, attempting to satisfy the concerns of both parties and trying to achieve a win-win solution that is mutually beneficial for both parties (Robbins and Judge, 2013). 
Synthesising the above literature, the researchers hypothesised that nAff would strengthen the positive relationship between EI and integrating conflict resolution style that focuses on high concern for others. The hypothesis developed :

Hla: NAff moderates the relationship between EI and integrating style

\section{METHODOLOGY}

The study employs a quantitative research technique, followed by a survey strategy and statistical analysis. It is a study with a positivist phenomenology.

The research was deductive as it started with examining the existing literature to establish a possible connection among the three key concepts of EI, nAff, and integrating conflict resolution style through testing established hypotheses. By exploiting the prevailing rich literature base, hypotheses are to be developed, tested, and confirmed.

The survey strategy used in this study attempts to explain what is happening in the social context and generalise the study findings. The study conducted a cross-sectional analysis using the collected data at a given time horizon only.

The study context was on Sri Lankan university undergraduates as there were many shreds of evidence on frequent student clashes and rivalry (Ruberu, 2003). Since university undergraduates are known to be the finest intellects who will be the prominent drivers of the country, addressing their critical behavioural issues seems obligatory.

The nature of the study aims to make statistical inferences of the population; thus, it is vital to select a representative sample. Therefore, the researchers used a convenience sampling (non-probability sampling) technique as it allowed the researcher ease of access to the respondents who enabled themselves to provide the desired information. This technique allowed the researcher to collect data at a lower cost and effort within a shorter duration despite the population scattered around the country.

A sample of 397 undergraduates covering all academic levels was selected representing certain universities to ensure the sample size's sufficiency (Krejcie and Morgan, 1970). The response rate was around 98 percent (388).

Table 1: Sample profile

\begin{tabular}{|c|c|c|c|}
\hline \multirow{2}{*}{$\begin{array}{c}\text { Demographic } \\
\text { Variable }\end{array}$} & \multirow[b]{2}{*}{ Category } & \multicolumn{2}{|c|}{ Frequency } \\
\hline & & $\begin{array}{c}\text { Frequenc } \\
\mathrm{y}\end{array}$ & $\begin{array}{c}\text { Percentage } \\
\%\end{array}$ \\
\hline \multirow[t]{2}{*}{ Gender } & Male & 62 & 16.0 \\
\hline & Female & 326 & 84.0 \\
\hline \multirow[t]{4}{*}{ Year } & Year 1 & 11 & 2.8 \\
\hline & Year 2 & 65 & 16.8 \\
\hline & Year 3 & 154 & 39.7 \\
\hline & Year 4 & 158 & 40.7 \\
\hline \multirow[t]{10}{*}{ University } & $\mathrm{CBO}$ & 27 & 7.0 \\
\hline & KLN & 61 & 15.7 \\
\hline & PDN & 2 & 0.5 \\
\hline & RUH & 39 & 10.1 \\
\hline & SEUSL & 3 & 0.8 \\
\hline & SJP & 40 & 10.3 \\
\hline & SUSL & 27 & 7.0 \\
\hline & UJA & 26 & 6.7 \\
\hline & UWU & 33 & 8.5 \\
\hline & WUSL & 130 & 33.5 \\
\hline \multirow[t]{9}{*}{ Degree } & $\begin{array}{l}\text { Agricultur } \\
\mathrm{e}\end{array}$ & 56 & 14.4 \\
\hline & $\mathrm{BA}$ & 10 & 2.6 \\
\hline & BBA & 17 & 4.4 \\
\hline & BBM & 48 & 12.4 \\
\hline & BCom & 13 & 3.4 \\
\hline & BSc - SCI & 42 & 10.8 \\
\hline & BSc-MGT & 188 & 48.5 \\
\hline & ICT & 9 & 2.3 \\
\hline & Other & 5 & 1.3 \\
\hline
\end{tabular}

The primary data gathered from the sample of 388 students as the study's unit of analysis was individual undergraduate students.

Since the study adopted a survey strategy, data were collected using a self-administered Likert scale questionnaire. Table 1 shows a sample profile. Eightyfour percent of those polled were female undergraduates, and the majority of them were in their third or fourth year of study. The study used already developed and tested scales presented in table 2 to 
enhance the validity and reliability of the research findings.

Table 2: Operationalization of the variables

\begin{tabular}{|l|l|}
\hline \multicolumn{1}{|c|}{ Variable } & \multicolumn{1}{|c|}{ Measurement } \\
\hline $\begin{array}{l}\text { EI } \\
\text { (Independent }\end{array}$ & $\begin{array}{l}\text { Wong and law emotional } \\
\text { intelligence scale (WLEIS) (1 = } \\
\text { Strongly Disagree to 7 = Strongly } \\
\text { Agree) } \\
\text { (Wong and Law, 2002) }\end{array}$ \\
\hline $\begin{array}{l}\text { Integrating } \\
\text { Style } \\
\text { (Dependent } \\
\text { Variable) }\end{array}$ & $\begin{array}{l}\text { Rahim Organizational Conflict } \\
\text { Inventory-II (ROCII) -Form C (1 = } \\
\text { Strongly Disagree to 5 = Strongly } \\
\text { Agree) } \\
\text { (Rahim, 1983) }\end{array}$ \\
\hline nAff & $\begin{array}{l}\text { Unified Motive Scales (UMS) (1 = } \\
\text { Strongly Disagree to 5 = Strongly } \\
\text { Agree) } \\
\text { (Moderator) }\end{array}$ \\
& Schönbrodt and Gerstenberg, 2012) \\
\hline
\end{tabular}

\section{RESULTS}

The Pearson correlations performed provided a deeper analysis of the direction and strength of the nexus between EI, nAff, and integrating style of conflict resolution. Table 2 illustrates the correlation results.

Table 3: Correlation matrix of the relationship among variables. Source: Survey Data

\begin{tabular}{|ll|l|l|}
\hline & & EI & $\begin{array}{l}\text { Integrating } \\
\text { Style }\end{array}$ \\
\hline $\mathbf{1}$ & EI & & \\
\hline $\mathbf{2}$ & Integrating Style & $.311^{* *}$ & \\
\hline $\mathbf{3}$ & nAff & $.238^{* *}$ & $.269^{* *}$ \\
\hline
\end{tabular}

Note. $\mathrm{N}=388, * * \mathrm{p}<.01$,

$\mathrm{EI}=$ Emotional Intelligence, $\mathrm{nAff}=$ Need for Affiliation

Source: Survey Data

Results indicate that, EI reported to have significant correlation with integrating style $(\mathrm{r}=.311, \mathrm{p}<.01)$. nAff is significant and moderately associated with integrating style $(r=.269, \mathrm{p}<.01)$. A simple regression model was used to test the hypothesis using regression analysis based on the independent variable (EI) relationship with the dependent variable (integrating style).

The statistical model is as follows;

$$
\mathbf{Y}=\mathbf{b} \mathbf{0}+\mathbf{b} \mathbf{1 X}
$$

The model was used to determine whether or not there was a statistically significant link between EI and integrating style through a simple regression model. There was a statistically significant positive correlation between EI and integrating style $(r=.311, p .01)$. The regression results are shown in Table 3.

Table 4. Hypothesis testing based on the regression model: EI and Integrating style

\begin{tabular}{|l|l|l|l|l|}
\hline \multicolumn{2}{|l|}{ Model } & $\begin{array}{l}\text { Coefficient } \\
\mathrm{B}\end{array}$ & $\mathrm{T}$ & Significance \\
\hline \multirow{2}{*}{1} & \multirow{2}{*}{\begin{tabular}{l} 
(Constant) \\
\cline { 2 - 5 }
\end{tabular}} & 2.594 & 13.731 & .000 \\
\hline & $\mathrm{EI}$ & .233 & 6.766 & .000 \\
\hline $\mathrm{R}$ & $.326^{* * *}$ & \\
\hline $\mathrm{R}^{2}$ & $.106^{* * *}$ & \\
\hline $\mathrm{F}$ & 45.773 & \\
\hline \multicolumn{2}{|l}{ Predictors: (Constant), EI } \\
\hline \multicolumn{2}{|l}{ Dependent Variable: Integrating style } \\
\hline
\end{tabular}

Note. $N=388, * * * p<.001, E I=$ Emotional Intelligence Source: Survey Data

Table 5. Hierarchical regression: moderating effect of nAff on the relationship between EI and integrating style

\begin{tabular}{|l|l|l|l|}
\hline Variable & Model 1 & Model 2 & Model 3 \\
\hline (Constant) & 3.866 & 3.866 & 3.857 \\
& $(192.969)$ & $(196.818)$ & $(192.585)$ \\
\hline $\mathrm{EI}$ & $.233^{* * *}$ & $.198^{* * *}$ & $202^{* * * *}$ \\
& $(6.766)$ & $(5.693)$ & $(5.826)$ \\
\hline $\mathrm{nAff}$ & - & $.158^{* * * *}$ & $.161^{* * *}$ \\
& & $(4.076)$ & $(4.162)$ \\
\hline EI_X_nAff & - & - & $.121^{*}$ \\
& & & $(2.082)$ \\
\hline $\mathrm{F}$ & 45.773 & 32.120 & 23.044 \\
\hline $\mathrm{R}^{2}$ & $.106^{* * *}$ & $.143^{* * *}$ & $.153^{* * *}$ \\
\hline$\Delta \mathrm{R}^{2}$ & - & $037^{* * *}$ & $.010^{*}$ \\
\hline a. Predictors: (Constant), EI & \\
\hline b. Predictors: (Constant), EI, nAff \\
\hline c. Predictors: (Constant), EI, nAff, EI_X_nAff \\
\hline d. Dependent Variable: Integrating Style \\
Note. *P<.05, **P<.01, ***P<.001 \\
EI=Emotional Intelligence, nAff = Need for Affiliation \\
Source: Survey Data
\end{tabular}


The results of the regression model indicated that the predictor variable explains 11 percent $(11 \%)$ of the variance in the outcome variable $(\mathrm{R} 2=.106, \mathrm{~F}(1,386)$ $=45.773, \mathrm{p}<.001)$. The results indicated that EI significantly predicts the selection of integrating style as a conflict resolution strategy $(\beta=.233, \mathrm{p}<.001)$. The two variables exhibit a significant positive relationship; hence the results of the research confirm hypothesis one (H1). Thus it concludes that EI is positively related to integrating conflict resolution style.

A key objective of this research was to ascertain how nAff moderates the relationship between EI and the integrating style of conflict resolution. When it comes to the relationship between emotional intelligence and the integrating conflict resolution style, that expects nAff to have a synergistic effect. Table 4 depicts the results, and the statistical model is as follows;

$$
\mathrm{Y}=\mathrm{b} 0+\mathrm{b} 1 \mathrm{X}+\mathrm{b} 2 \mathrm{Z}+\mathrm{b} 3 \mathrm{XZ}
$$

As shown in the table 4, the model indices in steps $1(\mathrm{~F}$ $(1,386)=45.773, \mathrm{p}<.001), 2(\mathrm{~F}(2,385)=32.120, \mathrm{p}<$ $.001)$ and $3(\mathrm{~F}(3,384)=23.044, \mathrm{p}<.001)$ are statistically significant. The model 1,2 and 3 explains a variance of $11 \%(\mathrm{R} 2=.106, \mathrm{~F}(1,386)=45.773$, $\mathrm{p}<.001), 14 \%(\mathrm{R} 2=.143, \mathrm{~F}(2,385)=32.120, \mathrm{p}<.001)$ and $15 \%(\mathrm{R} 2=.153, \mathrm{~F}(3,384)=23.044, \mathrm{p}<.001)$ in the integrating style respectively. The statistical scores of the $\operatorname{EI}(\beta=.202, p<.001)$, nAff $(\beta=.161, p<.001)$ and the interaction term $(\beta=.121, \mathrm{p}<.05)$ were significant. With the introduction of the interaction construct, the change of the $R 2$ value was significant $(\Delta R 2=0.010$, $p$ $<0.05)$ indicating that there is potentially significant moderation between EI and nAff on integrating style ( $\beta$ $=.121, \mathrm{p}<.05)$.

Performing a simple slope analysis helps to identify the type of interaction effect. Students' nAff levels are represented graphically in Figure 3 by three simple regression lines: the low, average, and high values. Figure 3 illustrates the three simple regressions drawn to detect the type of interaction effect of the EI and nAff on selecting the integrating style with preference.

The graph demonstrates that an increase in EI was significantly associated with selecting an integrating style, and nAff enhanced this relationship. It confirms that high EI students driven with nAff have more preference to select integrating style to resolve conflicts. Consequently, the conclusion is that the model supports hypothesis $\mathrm{H} 1 \mathrm{a}$ and proves a positive moderating effect of nAff on the relationship between EI and integrating style.

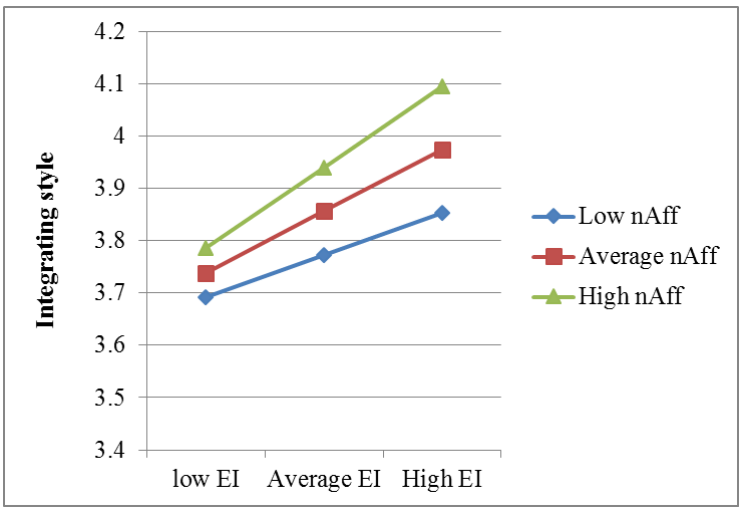

Figure 3: Moderating effects of nAff on the relationship between EI and integrating style Source: survey data

\section{DISCUSSION}

The research proposed that nAff influences the students' decision of conflict resolution and their EI level. Referring to past literature, the influence of nAff as the moderating factor on the relationship between EI and integrating style, specifically concerning the context of Sri Lankan state university undergraduates, remained unexplored. It is vital to test the influence of the level of EI and the motivational drive of a person in selecting a conflict resolution strategy to have a more accurate purview in finding solutions to undergraduate conflicts. The study provides a comprehensive insight into the aforementioned field.

The statistical analysis results revealed that integrating style was preferred by most of the students, confirming Chan, Sit, and Lau (2014). This behaviour may be a result of the cultural values held by the students. The study of Morris et al. (1998) affirms that cultural values influence conflict management behaviour. Asian culture leans towards collectivism, where they value group goals over individual goals, group concerns over individual concerns, and collective needs over individual needs (Ting-Toomey et al., 1991).

In answer to the research question of whether emotional intelligence influences selecting Integrating conflict 
resolution style, the outcomes concluded that EI is positively related to integrating conflict resolution styles. The findings confirm several other research findings (Jordan and Troth, 2002; Jones, 2000; Shih and Susanto, 2010; Gross and Guerrero, 2000; Chan, Sit, and Lau, 2014). People with higher emotional intelligence seek more collaborative solutions than those who lack emotional intelligence (Desivilya \& Yagil, 2005; Jordan \& Troth, 2002; Goleman, 1998). Integrating style is considered a more collaborative conflict resolution style (Gross \& Guerrero, 2000; Morrison, 2008). These characteristics may lead students to always put other people's interests as an essential consideration in solving conflicts; thus, the styles which comply with those characteristics may have become a priority in the selection decision.

The second research question was whether the need for affiliation moderates the relationship between emotional intelligence and integrating conflict resolution style. Studies suggest that nAff positively links with selecting a smoothing conflict resolution style (Jones and White, 1985). And the results support the positive moderating effect of nAff on integrating style. It implies that if a person has a high EI level, they tend to select the integrating style. That association further strengthens if motivational affiliation needs to drive that person. People with high EI interact well with people and possess good interpersonal skills (Goleman, 1998). People with affiliation motives seek social approval and typically desire to be fond of others and want others to like them (Lilly, Duffy, and Virick, 2006). Thus the findings may result from the complementing effect of a high emotionally intelligent person who drives from affiliation need concerning other party's needs through attempting to satisfy the concerns of both parties. That tries to achieve a win-win solution that is mutually beneficial for both parties (Robbins and Judge, 2013), preferring an integrating conflict resolution style.

At the theoretical level, this research contributes significantly to understanding the role of nAff in defining the relationship between EI and the integrating style of conflict resolution. Prior researchers have investigated the direct association between EI and conflict resolution strategies; (Ashkanasy and Daus,
2002; Bodtker and Jameson, 2001; Chan, Sit, and Lau, 2014; Di Fabio and Blustein, 2010; Jordan and Troth, 2004), EI and human motivational needs (Christie et al., 2007; Jones and White, 1985; Essop, 2015) and human motivational needs and conflict resolution (Fodor, 1985; Bell and Blakeney, 1977). This research uniquely explores the relationship between EI and integrating style of conflict resolution strategies, with nAff modeled as the moderator.

The research concluded that nAff enhances the link between EI and integrating style of conflict resolution strategy. Therefore, it implies that to foster an environment to increase the chances of selecting a more productive and collaborative conflict resolution approach by a student, a higher EI would matter, and a drive for affiliation matters along with high EI

Studies have shown that integrating style leads to creative solutions and is generally perceived as the most appropriate, most effective, and highly competent style in managing conflicts. Studies have revealed that a higher level of EI would direct people to select more collaborative conflict resolution styles (Antonioni, 1998; Ashkanasy and Daus, 2002; Bodtker and Jameson, 2001; Chan, Sit, and Lau, 2014; Di Fabio and Blustein, 2010; Jordan and Troth, 2004; Gross and Guerrero, 2000). According to this study, when students' EI and affiliation drives get stimulated, they are more likely to choose effective conflict resolution methods like integrating style. Thus one of the practical implications of this study is to elevate the level of emotional intelligence of the students. In the initial stage of the university academic life, the university system can introduce programs to elevate the students' level of emotional intelligence. The outcome of these programmes would help them to select more appropriate and productive conflict resolution styles.

The study also found that by increasing the students' level of emotional intelligence and stimulating their affiliation drives, they can select more productive conflict resolution approaches such as integrating style. Therefore, giving them opportunities to enhance the affiliation with EI development programmes under University Grants Commission before the student are enrolled to the universities (i.e., secondary education level and induction level) would yield better results. 


\section{CONCLUSION}

The outcomes concluded that EI is positively related to integrating conflict resolution styles. However, the research outcomes need examination in the light of several cautions to put the findings in perspective.

These limitations can potentially impact the generalisability of the research outcomes beyond the context of the present research. The study sample was limited to state university undergraduates, employed a non-probability sampling technique that acquires data using convenience sampling. In terms of the survey methodology, this research relied on self-reported data. Given the nature of the acquired data, the possibility of self-report bias may occur. Moreover, the model only examines a fraction of human motivational needs, EI, and conflict resolution strategies where other unmeasured factors such as personality, values, and culture could influence. Future researchers could address the limitations mentioned above and direct their studies to address the remaining gaps.

\section{REFERENCES}

Antonioni, D. (1998). Relationship between the big five personality factors and conflict management styles. International journal of conflict management, 9(4).

Ashkanasy, N.M. and Daus, C.S. (2002). Emotion in the workplace: The new challenge for managers. Academy of Management Perspectives, 16(1), pp.76-86.

Barbuto Jr, J.E. and Xu, Y. (2006). Sources of motivation, interpersonal conflict management styles, and leadership effectiveness: A structural model. Psychological Reports, 98(1), pp.3-20.

Bell, E.C., and Blakeney, R.N. (1977). Personality correlates of conflict resolution modes. Human Relations, 30(9), pp.849-857.

Bodtker, A.M. and Jameson, J.K. (2001). Emotion in conflict formation and its transformation: Application to organizational conflict management. International journal of conflict management, 12(3).

Chan, J.C., Sit, E.N. and Lau, W.M. (2014). Conflict management styles, emotional intelligence and implicit theories of personality of nursing students: A crosssectional study. Nurse education today, 34(6), pp.934939.

Chatman, J.A. and Barsade, S.G. (1995). Personality, organizational culture, and cooperation: Evidence from a business simulation. Administrative science quarterly, pp.423-443.

Cherniss, C. and Adler, M. (2000). Promoting emotional intelligence in organizations: Make training in emotional intelligence effective. American Society for Training and Development.

Christie, A., Jordan, P., Troth, A. and Lawrence, S. (2007). Testing the links between emotional intelligence and motivation. Journal of Management and Organization, 13(3), p.212.

Chun, J.S. and Choi, J.N. (2014). Members' needs, intragroup conflict, and group performance. Journal of Applied Psychology, 99(3), p.437.

Darling, J.R. and Walker, W.E. (2001). Effective conflict management: use of the behavioral style model. Leadership \& Organization Development Journal.

De Dreu, C.K. and Van de Vliert, E. eds. (1997). Using conflict in organizations. Sage.

Desivilya, H.S., and Yagil, D. (2005). January. The role of emotions in conflict management: The case of work teams. In IACM 17th Annual Conference Paper.

Di Fabio, A. and Blustein, D.L. (2010). Emotional intelligence and decisional conflict styles: Some empirical evidence among Italian high school students. Journal of Career Assessment, 18(1), pp.7181.

Eadie, W.F. and Nelson, P.E. (2001). The language of conflict and resolution. Sage.

Essop, R. (2015). The impact of emotional intelligence on employee motivation in the construction sector (Doctoral dissertation).

Fleetwood, K.L. (1987). The conflict management styles and strategies of educational managers (Master's thesis, University of Delaware). 
Fodor, E.M. (1985). The power motive, group conflict, and physiological arousal. Journal of Personality and Social Psychology, 49(5), p.1408.

Goleman, D. (1998). Working with emotional intelligence. Bantam.

Gross, M.A. and Guerrero, L.K. (2000). Managing conflict appropriately and effectively: An application of the competence model to Rahim's organizational conflict styles. International journal of conflict management, 11(3).

Hegar, K.W. (2012). Modern human relations at work. Cengage Learning.

Hennayake, S.K. (2008). The fundamental threat to Sri Lankan University education. Asian Tribune, 20. Available at:

http://www.asiantribune.com/?q=node/14294

(Accessed August 16, 2020)

Jehn, K.A. (1997). A qualitative analysis of conflict types and dimensions in organizational groups. Administrative science quarterly, pp.530-557.

Jones, R.E. and White, C.S. (1985). Relationships among personality, conflict resolution styles, and task effectiveness. Group \& Organization Studies, 10(2), pp.152-167.

Jones, T. (2000). The Language of Conflict and resolution. Thousand Oaks: CA: Sage.

Jordan, P.J. and Troth, A.C. (2002). Emotional intelligence and conflict resolution: Implications for human resource development. Advances in developing human resources, 4(1), pp.62-79.

Jordan, P.J. and Troth, A.C. (2002a). Emotional intelligence and conflict resolution in nursing. Contemporary Nurse, 13(1), pp.94-100.

Jordan, P.J. and Troth, A.C. (2004). Managing emotions during team problem solving: Emotional intelligence and conflict resolution. Human performance, 17(2), pp.195-218.

Kilmann, R.H. and Thomas, K.W. (1977). Developing a forced-choice measure of conflict-handling behavior: The" MODE" instrument. Educational and psychological measurement, 37(2), pp.309-325.
Krejcie, R.V. and Morgan, D.W. (1970). Determining sample size for research activities. Educational and psychological measurement, 30(3), pp.607-610.

Lam, L.T. and Kirby, S.L. (2002). Is emotional intelligence an advantage? An exploration of the impact of emotional and general intelligence on individual performance. The journal of Social Psychology, 142(1), pp.133-143.

Lilly, J.D., Duffy, J.A. and Virick, M. (2006). A gender-sensitive study of McClelland's needs, stress, and turnover intent with work-family conflict. Women in Management Review.

Ma, Z. (2005), June. Exploring the relationships between the big five personality factors, conflict styles, and bargaining behaviors. In IACM 18th Annual Conference.

Mayer, J.D., Salovey, P. and Caruso, D.R. (2008). Emotional intelligence: New ability or eclectic traits?. American psychologist, 63(6), p.503.

McClelland, D.C. (1987). Human motivation. CUP Archive.

Morris, M.W., Williams, K.Y., Leung, K., Larrick, R., Mendoza, M.T., Bhatnagar, D., Li, J., Kondo, M., Luo, J.L. and Hu, J.C. (1998). Conflict management style: Accounting for cross-national differences. Journal of international business studies, 29(4), pp.729-747.

Morrison, J. (2008). The relationship between emotional intelligence competencies and preferred conflict-handling styles. Journal of Nursing Management, 16(8), pp.974-983.

Mrayyan, M.T., Modallal, R., Awamreh, K., Atoum, M., Abdullah, M. and Suliman, S. (2008). Readiness of organizations for change, motivation and conflicthandling intentions: Senior nursing students' perceptions. Nurse Education in Practice, 8(2), pp.120-128.

Pondy, L.R. (1967). Organizational conflict: Concepts and models. Administrative science quarterly, pp.296320. 
Popescu, C. and Vasilescu, L. (20120, May. Conflict-A permanent coordinate of existence. In International Conference of Scientific Paper, AFASES pp. 24-26.

Raeisi, M., Hadadi, N., Faraji, R. and Salehian, M.H. (2012). McClelland's motivational needs: A case study of physical education teachers in West Azarbaijan. European Journal of Experimental Biology, 2(4), pp.1231-1234.

Rahim, M.A. (1983). A measure of styles of handling interpersonal conflict. Academy of Management Journal, 26(2), pp.368-376.

Rahim, M.A. (2002). Toward a theory of managing organizational conflict. International journal of conflict management, 13(3).

Rahim, M.A., Psenicka, C., Polychroniou, P. and Zhao, J.H. (2002). A model of emotional intelligence and conflict management strategies: A study in seven countries. International Journal of Organizational Analysis, 10(4).

Ramlall, S. (2004). A review of employee motivation theories and their implications for employee retention within organizations. Journal of American academy of business, 5(1/2), pp.52-63.

Robbins, S.P. and Judge, T.A. (2013). Organizational Behavior. New Jersey: Person Education.

Ruberu, R. (2003). Indiscipline in Sri Lankan Universities. The Island Newspaper, 30 January. (Accessed $1^{\text {st }}$ August 2020).

Rybnicek, R., Bergner, S. and Gutschelhofer, A. (2019). How individual needs influence motivation effects: a neuroscientific study on McClelland's need theory. Review of Managerial Science, 13(2), pp.443482.

Salovey, P. and Mayer, J.D. (1990). Emotional intelligence. Imagination, cognition, and personality, 9(3), pp.185-211.

Schönbrodt, F.D. and Gerstenberg, F.X. (2012). An IRT analysis of motive questionnaires: The unified motive scales. Journal of Research in Personality, 46(6), pp.725-742.
Schultheiss, O.C., Wirth, M.M., Waugh, C.E., Stanton, S.J., Meier, E.A. and Reuter-Lorenz, P. (2008). Exploring the motivational brain: effects of implicit power motivation on brain activation in response to facial expressions of emotion. Social Cognitive and Affective Neuroscience, 3(4), pp.333-343.

Shih, H.A. and Susanto, E. (2010). Conflict management styles, emotional intelligence, and job performance in public organizations. International journal of conflict management.

Spielberger, C. (2004). Encyclopedia of applied psychology. Academic Press.

Thomas, K.W. (1992). Conflict and negotiation processes in organizations.

Ting-Toomey, S., Gao, G., Trubisky, P., Yang, Z., Kim, H.S., Lin, S.L. and Nishida, T. (1991). Culture, face maintenance, and styles of handling interpersonal conflict: A study in five cultures. International Journal of conflict management.

Uduji, J.I. and Ankeli, M.O. (2013). Needs for achievement, affiliation, and power: The possible sales manager's actions for exceptional salesforce performance. Research Journal of Finance and Accounting, 4(9), pp.96-103.

Weeramunda, A.J. (2008). Socio-political impact of student violence and indiscipline in universities and tertiary education institutes. Colombo: National Education Commission, Sri Lanka.

Wong, C.S. and Law, K.S. (2002). The effects of leader and follower emotional intelligence on performance and attitude: An exploratory study. The leadership quarterly, 13(3), pp.243-274. 